\title{
Thymidine phosphorylase expression in Kaposi
}

\section{sarcoma}

\author{
M A Dada, C H Boshoff, M A Comley, H Turley, J W Schneider, R Chetty, \\ K C Gatter
}

\author{
University \\ Department of \\ Cellular Science, \\ University of Oxford \\ M A Dada \\ M A Comley \\ H Turley \\ K C Gatter \\ Chester Beatty \\ Institute of Research, \\ London \\ C H Boshoff \\ Department of \\ Anatomical Pathology, \\ University of \\ Stellenbosch, \\ Cape Town, \\ South Africa \\ J W Schneider \\ Department of \\ Anatomical Pathology, \\ University of Natal, \\ Durban, South Africa \\ R Chetty \\ Correspondence to: \\ Dr M A Dada, University \\ Department of Cellula \\ Science, University of \\ Oxford, Level 4, Academic \\ Block, John Radcliffe \\ Hospital, Oxford OX3 9DU. \\ Accepted for publication \\ 16 February 1996
}

\begin{abstract}
Aims-To examine the immunohistochemical distribution of thymidine phosphorylase (TP) in all clinicopathological subtypes of Kaposi sarcoma.

Methods-Thirty two biopsy specimens of Kaposi sarcoma (29 patients) were studied. Six of these patients represented classic, six endemic, eight HIV associated, seven post-immunosuppression/transplant related, and two unclassifed variants of $\mathrm{Ka}$ posi sarcoma. The average age was 49 years (range 22-83 years) and the male: female ratio $24: 5$. Four samples of angiosarcoma and one of spindle cell haemangioendothelioma were stained in parallel. All specimens were fixed in formalin, embedded in paraffin wax and processed routinely. Immunohistochemistry was carried out using an antibody directed against CD31 (JC70) and the monoclonal antibody P-GF.44C against TP.

Results-All biopsy specimens showed immunoexpression for TP. The spindle cell component stained more strongly than newly formed endothelium lined vessels and normal, resident vessels at a distance from the lesions.

Conclusions-The strong immunoexpression of TP suggests up-regulation of TP and a role for TP in angiogenesis in Kaposi sarcoma. The mechanism for the up-regulation of TP remains unknown, but viral infections may trigger it. The differential staining of the various cell components of Kaposi sarcoma also suggest that TP either plays a role in the differentiation and maturation of Kaposi sarcoma or is a reflection of such changes. ( $f$ Clin Pathol 1996;49:400-402)
\end{abstract}

Keywords: Kaposi sarcoma, angiogenesis, thymidine phosphorylase, platelet derived endothelial cell growth factor, immunohistochemistry.

Thymidine phosphorylase (TP) (previously known as platelet derived endothelial cell growth factor (PD-ECGF)) has been shown to be an angiogenic factor in both in vivo assays and in tumour systems. ${ }^{1}$ TP is a single chain acidic polypeptide with a relative molecular mass of $45000 .^{2}$ TP catalyses breakdown of thymidine to deoxyribose-1-phosphate and thymine. Deoxyribose displays angiogenic activity in the chick chorioallantoic membrane (CAM assay). ${ }^{3}$ TP is postulated to promote endothelial cell proliferation by reducing thy- midine concentrations which would otherwise inhibit endothelial cell growth. ${ }^{4}$ Increased TP activity, therefore, could promote endothelial cell growth and increased production of deoxyribose, with subsequent promotion of angiogenesis.

In normal human tissues TP is expressed in endothelial cells, macrophages, stromal cells, glial cells, and epithelia such as skin, salivary gland and breast, where it is involved in normal cellular differentiation and maturation. ${ }^{1}$ In non-neoplastic conditions TP plays a role in endothelial repair and angiogenesis associated with wound healing. ${ }^{5}$

Increased TP expression also occurs in areas of angiogenesis within tumours. In breast and ovarian cancer, angiogenesis is associated with up-regulation of TP activity..$^{6-8}$

Kaposi sarcoma is a vascular tumour characterised histologically by a mixture of proliferating spindle cells, endothelial lined vascular spaces and variable inflammatory cell infiltrates. Cultured Kaposi sarcoma derived cell lines secrete a series of cytokines such as Oncostatin $M,{ }^{9}$ tumour necrosis factor $\alpha$ (TNF $\alpha$ ), endothelial cell growth factor (TP), interleukin $1 \beta$ (IL-1 $\beta$ ), interleukin-6 (IL-6), basic fibroblast growth factor (bFGF) ${ }^{10}$ fibroblast growth factor 5 (FGF-5), PDGF-A, and PDGF-B. ${ }^{1011}$ Expression of IL-6 receptor (IL6-R), PDGF $\alpha$ and $\beta$ receptors has also been shown. ${ }^{11}$ bFGF and HIV-1 Tat protein have a synergistic effect on Kaposi sarcoma cell proliferation. ${ }^{1213}$ This may explain why HIV associated Kaposi sarcoma is more frequent and aggressive than classic Kaposi sarcoma where only bFGF is present. ${ }^{12}$

As angiogenesis is crucial to the growth of Kaposi sarcoma, and TP is a known angiogenic factor, we explored TP expression in Kaposi sarcoma by using immunohistochemistry. Due to the possible role of TP in cellular differentiation we also examined the expression of TP in the various morphological components of Kaposi sarcoma.

\section{Methods}

Thirty two biopsy specimens of Kaposi sarcoma (29 patients) were studied. Twenty five samples of Kaposi sarcoma from 22 patients were retrieved from the Department of Anatomical Pathology, University of Stellenbosch, Cape Town, South Africa. An additional seven samples of Kaposi sarcoma were obtained from the Chester Beatty Research Institute, London. Of the 32 biopsy specimens, four were of non- 


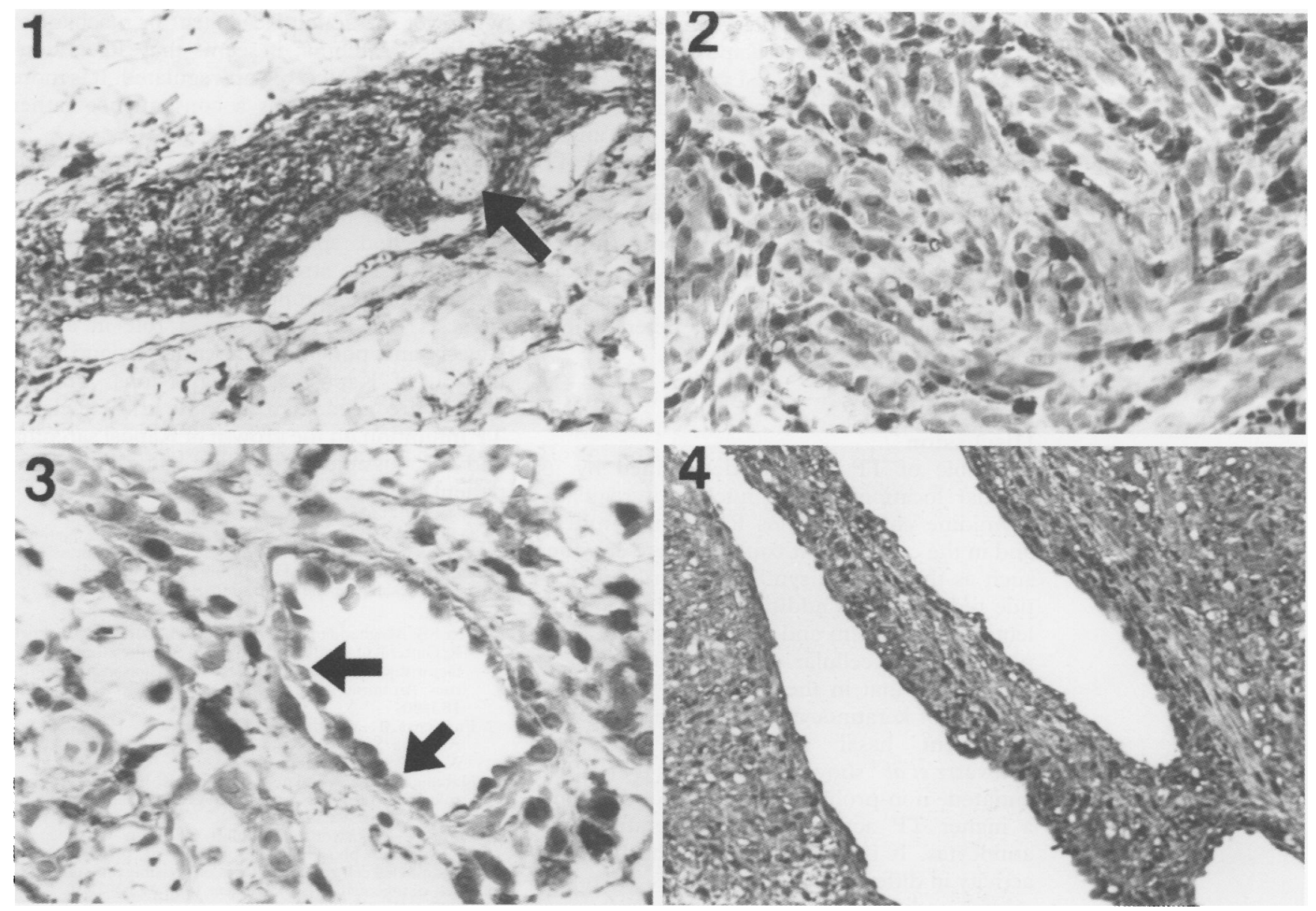

Figure 1 Panel 1: Spindle cell nodule showing a perivascular location with perineural invasion (arrow). Intense staining with TP is present in the spindle cells whilst adjacent collagen is negative. Panel 2: Spindle cells at higher magnification exhibiting intense nuclear and cytoplasmic staining with TP in many cells. Panel 3: Well formed endothelial lined vascular channel displaying a heterogeneous staining pattern-that is, co-existing positive and negative (arrows) staining for TP. Panel 4: Spindle cell haemangioendothelioma stained by TP demonstrating strong nuclear endothelial and spindle cell positivity. Occasional endothelial cells in the vessel show no staining.

cutaneous origin (one each involving the following sites: deep soft tissue, hard and soft palate and liver). Four samples of angiosarcoma and one of spindle cell haemangioendothelioma were stained in parallel to compare staining patterns of known vascular neoplasms with that of Kaposi sarcoma, a putative vascular tumour.

All cases were fixed in formalin, embedded in paraffin wax and processed routinely. Haematoxylin and eosin sections were evaluated to confirm the histological diagnoses. Immunohistochemistry was performed on the paraffin wax embedded tissue sections using antibodies directed against CD31 (JC70) (Dako, High Wycombe, UK) and the monoclonal antibody P-GF.44C, directed against TP. ${ }^{1}$ Both antibodies were used as neat supernatant. A two step technique using biotinylated goat anti-mouse immunoglobulin and $\mathrm{ABC}$ horse radish peroxidase was used for staining with P-GF.44C and JC70. Diaminobenzidine

Table 1 Clinical details of the patients in this study

\begin{tabular}{lccl}
\hline Clinical type of Kaposi sarcoma & $n$ & Male:female ratio & Age range (in years) \\
\hline Classic & 6 & $6: 0$ & $54-83$ \\
Endemic (African) & 6 & $6: 0$ & $41-74$ \\
HIV associated (epidemic) & 8 & $5: 3$ & $23-48$ \\
Post-immunosuppression/transplant related & 7 & $5: 2$ & $22-55$ \\
Unclassified/HIV status unknown & 2 & $2: 0$ & $27-34$ \\
Total & 29 & $24: 5$ & $22-83$ \\
& & & (mean 49) \\
\hline
\end{tabular}

(DAB) was used as chromogen in both instances. Microwave pretreatment was used to enhance antigen retrieval for TP. Omission of the primary antibody was used as a negative control.

\section{Results}

The clinical details of the Kaposi sarcoma cases are summarised in table 1 . All specimens showed nuclear and cytoplasmic immunoexpression for TP. In all samples of Kaposi sarcoma there was strong but patchy staining of spindle cells (fig 1, panels 1 and 2). There was weaker staining of endothelium that lined newly formed vessels. Within each case spindle cells and vascular channels showed a heterogeneous pattern of staining - that is, some cells were positive and others negative (fig 1, panel 3). There were no morphological differences between the positive and negative cells. Furthermore, there was variation in staining between lesions. Normal vascular endothelium away from the lesions stained focally, but less strongly, than the spindle cells or vascular endothelium within Kaposi sarcoma. The samples that included skin revealed positive staining of sweat ducts and the epidermis with accentuation of the basal layer. ${ }^{1}$ Dermal collagen and fibroblastic cells were negative (fig 1, panel 1). Inflammatory cells (macrophages and 
plasma cells mainly) showed expression of TP in all those specimens of Kaposi sarcoma containing inflammatory cells. Lymphocytes in the inflammatory infiltrate, however, did not show immunopositivity for TP. The four angiosarcoma samples showed heterogeneous TP immunoexpression similar to that encountered with Kaposi sarcoma lesions. The case of spindle cell haemangioendothelioma showed strong spindle cell positivity with TP. Endothelial cells lining the cavernous haemangiomatous areas also displayed a heterogenous pattern of staining (fig 1 , panel 4).

\section{Discussion}

The role of TP may be determined by its cellular location. In the nucleus it regulates thymidine concentrations for DNA synthesis and in the cytoplasm it could regulate enzymes such as thymidylate synthase and ribonucleotide reductase. ${ }^{1}$ In addition to its role in nucleotide metabolism and angiogenesis, TP may play a role in cellular differentiation. ${ }^{1}$ Fox et $a l^{1}$ showed that in the skin there was diffuse staining of keratinocytes at all levels but with prominent basal accentuation. However, Schwartz et al $^{14}$ showed in cell lines that differentiated, non-proliferating keratinocytes have a higher TP activity than proliferating keratinocytes. It is postulated that the high TP activity in differentiated cells breaks down thymidine, reducing the nucleotide precursor pool available for DNA synthesis. This apparent discrepancy between the two studies may be ascribed to differences in results obtained from in vivo and in vitro model systems.

The immunopositivity of endothelial cells and the spindle cell component of Kaposi sarcoma with TP suggests a role for this enzyme in the angiogenesis of Kaposi sarcoma. Stronger TP expression in spindle cells than in the vascular endothelial components of Kaposi sarcoma may indicate that TP is up-regulated and plays a role in the differentiation and progression of Kaposi sarcoma.

Recent research has shown that all epidemiological subtypes of Kaposi sarcoma are associated with a newly discovered virus, referred to as the human herpesvirus-like agent or the Kaposi sarcoma herpes virus (KSHV). ${ }^{1516}$ Although KSHV and cytomegalovirus have not been shown to be causally linked to Kaposi sarcoma, ${ }^{17}$ it is suggested that these viruses may still play a role in the pathogenesis of Kaposi sarcoma. Whilst a viral aetiology is conjectural, it is possible that a viral infection may be the trigger for the up-regulation of TP seen in our cases of Kaposi sarcoma. This may be mediated by cytokines released by inflammatory cells. Therefore, the inflammatory cell component, which is usually present in the early Kaposi sarcoma lesions, may be important in the induction of TP and hence angiogenesis and progression of lesions. Against a viral aetiological trigger is the failure to demonstrate a viral agent in every case of Kaposi sarcoma.
Whatever the aetiological agent or mechanism in Kaposi sarcoma, it seems that TP is consistently and noticeably up-regulated. It is more than likely that this is a consequence rather than a direct cause of the lesions.

We have demonstrated that TP is expressed in all epidemiological forms of Kaposi sarcoma as well as in other vascular tumours (angiosarcoma and spindle cell haemangioendothelioma). The stronger expression of TP in the spindle cell component of Kaposi sarcoma suggests that TP may play a role in angiogenesis and possible differentiation and maturation of Kaposi sarcoma lesions. Further studies are needed to appraise the effects of TP inhibition on the growth of Kaposi sarcoma and the possible therapeutic value thereof in patient management.

Dr Dada was supported by a travel grant from the National Cancer Association of South Africa. The authors express their sincere thanks to Dr Steve Fox for his advice and help and D Kingsley Micklem for the illustrations.

1 Fox SB, Moghaddam A, Westwood M, Turley H, Bicknell $\mathrm{R}$, Gatter KC, et al. Platelet-derived endothelial cell growth factor/thymidine phosphorylase expression in normal tisfactor/thymidine phosphorylase expression in normal tis-
sues: An immunohistochemical study. F Pathol 1995;176: sues: An

2 Furukawa T, Yoshimura A, Sumizawa T, Haraguchi $M$, Akiyama S, Fukui K, et al. Angiogenic factors (letter). Nature 1992;356:668.

3 Haraguchi M, Kazutaka M, Uemura K, Sumizawa T, Furukawa $\mathrm{T}$, Yamada $\mathrm{K}$, et al. Angiogenic activity of enzymes. Nature 1994;368:198.

4 Finnis C, Dodsworth N, Pollitt CE, Carr G, Sleep D. Thymidine phosphorylase activity of platelet-derived endothelial cell growth factor is responsible for endothelial cell mitogenicity. Eur 7 Biochem 1993;212:201-10.

5 Blood CH, Zetter BR. Tumour interactions with the vasculature: angiogenesis and tumor metastasis. Biochim Culature: angiogenesis and tum

6 Reynolds K, Farzaneh F, Collins WP, Campbell S, Bourne TH, Lawton F, et al. Association of ovarian malignancy with expression of platelet-derived endothelial cell growth factor. $\mathcal{F}$ Natl Cancer Inst 1994;86:1234-8.

7 Moghaddam A, Zhang H-T, Fan T-P, Hu DE, Lees VC, Turley $\mathrm{H}$, et al. Thymidine phosphorylase is angiogenic and promotes tumor growth. Proc Natl Acad Sci USA 1995;92:998-1002.

8 Yoshimura A, Kuwazuru Y, Furukawa T, Yoshida H, Yamada K, Akiyama S. Purification and tissue distribution of human thymidine phosphorylase; high expression in lymphocytes, reticulocytes and tumours. Biochim Biophys Acta 1990;1034:107-13.

9 Cai J, Gill PS, Masood R, Chandrasoma P, Jung B, Law $\mathrm{RE}$, et al. Oncostatin-M is an autocrine growth factor in $\mathrm{RE}$, et al. Oncostatin-M is an autocrine growth
Kaposi's sarcoma. Am $\mathcal{F}$ Pathol 1994;145:74-9.

10 Miles SA, Rezai AR, Salazar-Gonzalez JF, Vander Meyden M, Stevens RH, Logan DM, et al. AIDS Kaposi sarcoma derived cells produce and respond to interleukin 6 . Proc Natl Acad Sci USA 1990;87:4068-72.

11 Sturzl M, Roth WK, Brockmeyer NH, Zietz C, Speiser B, Hofschneider PH. Expression of platelet-derived growth factor and its receptor in AIDS-related Kaposi sarcoma in vivo suggest paracrine and autocrine mechanisms of tumor maintenance. Proc Natl Acad Sci USA 1992;89: tumor ma.

12 Ensoli B, Gendelman R, Markham P, Fiorelli V, Colombini $\mathrm{S}$, Raffeld $M$, et al. Synergy between basic fibroblast
growth factor and HIV-1 Tat protein in induction of growth factor and HIV-1 Tat protein in
Kaposi's sarcoma. Nature 1994;371:674-80.

13 Fiorelli V, Gendelman R, Samaniego F, Markham PD Ensoli B. Cytokines from activated T cells induce norma endothelial cells to acquire the phenotypic and functional features of AIDS-Kaposi's sarcoma spindle cells. $\mathcal{F}$ Clin Invest 1995;95:1723-34.

14 Schwartz PM, Barnett SK, Reuveni H. Thymidine salvage changes with differentiation in human keratinocytes in vitro. F Invest Dermatol 1991;97:1057-60.

15 Dupin N, Grandadam M, Calvez V, Gorin I, Aubin JT, Havard S, et al. Herpesvirus-like DNA sequences in patients with Mediterranean Kaposi's sarcoma. Lancet 1995;345:761-2.

16 Huang YQ, Li JJ, Kaplan MH, Poiesz B, Katabira E, Zhang WC, et al. Human herpesvirus-like nucleic acid in various forms of Kaposi's sarcoma. Lancet 1995;345:759-61.

17 Kempf W, Adams V, Pfaltz M, Gorin I, Aubin JT, Havard S, et al. Human herpesvirus type 6 and cytomegalovirus in AIDS-associated Kaposi's sarcoma. No evidence for an in AIDS-associated Kaposi's sarcoma. No evidence for 